\title{
Cancer symptom awareness and barriers to symptomatic presentation in England-are we clear on cancer?
}

\author{
M Niksic ${ }^{*, 1}$, B Rachet ${ }^{2}$, F G Warburton ${ }^{1}$, J Wardle ${ }^{3}$, A J Ramirez ${ }^{1}$ and L J L Forbes ${ }^{1}$ \\ ${ }^{1}$ Promoting Early Cancer Presentation Group, King's College London, Guy's Hospital Campus, 42 Weston Street, London SE1 \\ 3QD, UK; ${ }^{2}$ Cancer Research UK Cancer Survival Group, London School of Hygiene and Tropical Medicine, Keppel Street, London \\ WC1E 7HT, UK and ${ }^{3}$ Health Behaviour Research Centre, Department of Epidemiology and Public Health, University College \\ London, Gower Street, London WC1E 6BT, UK
}

Background: Low cancer awareness may contribute to delayed diagnosis and poor cancer survival. We aimed to quantify sociodemographic differences in cancer symptom awareness and barriers to symptomatic presentation in the English population.

Methods: Using a uniquely large data set $(n=49270)$, we examined the association of cancer symptom awareness and barriers to presentation with age, gender, marital status and socio-economic position (SEP), using logistic regression models to control for confounders.

Results: The youngest and oldest, the single and participants with the lowest SEP recognised the fewest cancer symptoms, and reported most barriers to presentation. Recognition of nine common cancer symptoms was significantly lower, and embarrassment, fear and difficulties in arranging transport to the doctor's surgery were significantly more common in participants living in the most deprived areas than in the most affluent areas. Women were significantly more likely than men to both recognise common cancer symptoms and to report barriers. Women were much more likely compared with men to report that fear would put them off from going to the doctor.

Conclusions: Large and robust socio-demographic differences in recognition of some cancer symptoms, and perception of some barriers to presentation, highlight the need for targeted campaigns to encourage early presentation and improve cancer outcomes.

Cancer survival in England is lower than in other high-income Western countries (Coleman et al, 2011). About 6000 deaths per year could be avoided if the 5-year cancer survival rate in England was the same as the Western European average (Abdel-Rahman et al, 2009). Breast, bowel and lung cancer accounted for approximately half of these avoidable deaths. Late stage at diagnosis contributes to excess deaths in England, along with the rest of the United Kingdom, from breast (Møller et al, 2010), bowel (Maringe et al, 2013) and lung cancer (Walters et al, 2013). A longer time interval from the onset of symptoms to the first presentation to a doctor, often referred to as prolonged 'patient interval', is likely to contribute to late stage at diagnosis (Lyratzopoulos et al, 2012a).

People who do not recognise that unexplained symptoms may be due to cancer are more likely to delay seeking medical help (Macleod et al, 2009; Forbes et al, 2014). In a recent English study, cancer patients who reported that they had not realised that their symptoms were serious were twice as likely to have taken $>3$ months from first noticing a symptom to seeing a doctor, in comparison with those who did not report this (Forbes et al, 2014). In addition, people reporting more barriers to symptomatic

*Correspondence: M Niksic; E-mail: maja.niksic@kcl.ac.uk

Received 14 January 2015; revised 5 April 2015; accepted 22 April 2015;

published online 30 June 2015

(c) 2015 Cancer Research UK. All rights reserved 0007-0920/15

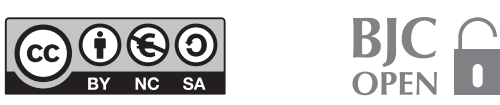


presentation were more likely to say they would delay seeking medical help (Robb et al, 2009; Simon et al, 2010).

In a recent population-based study, perceived barriers to symptomatic presentation were more common in the United Kingdom than in other high-income countries with similar healthcare systems (Forbes et al, 2013). For example, being 'worried about wasting the doctor's time' was perceived as a barrier to going to the doctor with a symptom that might be serious by $34 \%$ of UK participants, $21 \%$ of Canadians and only $9 \%$ of Swedes. Increased barriers to presentation in the United Kingdom might contribute to lower cancer survival, particularly if people lack awareness about potential cancer symptoms.

Cancer symptom awareness is lower and barriers to symptomatic presentation are more commonly reported among people of lower socio-economic position (SEP) (Brunswick et al, 2001; Robb et al, 2009), and older people (Linsell et al, 2008). These may contribute to the pattern of more advanced cancer at diagnosis and lower cancer survival in these groups (Rachet et al, 2010; Lyratzopoulos et al, 2012b). However, studies of cancer awareness and barriers to presentation have included few people from the oldest and most socio-economically disadvantaged groups (Robb et al, 2009; Simon et al, 2010; Forbes et al, 2013). Therefore, these studies lack power to comprehensively examine socio-demographic differences in recognition of cancer symptoms and perception of barriers in the population. In addition, few studies have used validated measures (such as Robb et al, 2009; Simon et al, 2010).

Tailoring to the target population is critical to the success of behavioural public health campaigns (NICE, 2007). We aimed to quantify socio-demographic differences in cancer symptom awareness and barriers to symptomatic presentation in the English population, to inform the development of effective campaigns to promote early presentation and to improve cancer survival.

\section{MATERIALS AND METHODS}

The data set included 18 cross-sectional surveys across England that used the Cancer Research UK Cancer Awareness Measure (CAM; Stubbings et al, 2009) - a validated measure of cancer awareness-during 2009/2011. The surveys were coordinated by the National Awareness and Early Diagnosis Initiative (NAEDI), which encouraged local health bodies to measure cancer awareness in their areas to inform commissioning of health services (Cancer Research UK, 2011). Different health bodies used the CAM for a variety of reasons, such as needs assessment or evaluation of local campaigns to increase awareness. All surveys were conducted before launching the first national campaigns in 2012 (Power and Wardle, 2015). We excluded surveys that evaluated local cancer awareness campaigns, such as the post-intervention survey in Greater Manchester and Cheshire. Surveys were carried out in urban and rural areas, in the North, South, West and East of England (Supplementary Material 1). Participants in eight surveys were recruited using random probability sampling from the electoral roll, commercial telephone listings or the postal address file, whereas 10 surveys used other types of sampling, such as approaching people on the street or knocking door-to-door (Supplementary Material 1).

Participants were interviewed using the CAM either face to face ( $84 \%)$ or by telephone (16\%). We analysed nine questions assessing cancer symptom awareness and 10 questions assessing barriers to presentation. Cancer symptom awareness was measured using the question: 'The following may or may not be warning signs of cancer. We are interested in your opinion. Do you think $X$ is a warning sign for cancer?' (Yes/No/Don't know). Barriers to presentation were assessed using the question: 'Sometimes people put off going to see the doctor, even when they have a symptom that they think might be serious. These are some of the reasons people give for delaying. Could you say if any of these might put you off going to the doctor?' (Yes often/Yes sometimes/No/Don't know).

Analysis. We added up 'Yes' responses to the questions about cancer symptoms and analysed them as a cancer symptom awareness score. Participants were considered to report a barrier if their response was 'Yes often' or 'Yes sometimes' to questions about barriers to presentation. We added up these responses to generate a barriers score. We considered 'No' and 'Don't know' responses as lack of awareness or lack of barriers. Descriptive statistics were calculated for participants' socio-demographic characteristics (age groups, gender, marital status and SEP) in relation to cancer awareness and barrier score. We estimated SEP using an area-based measure, income domain of the indices of multiple deprivation (IMD; Department for Communities and Local Government, 2010), which we called 'area income deprivation'; and two individual level measures, educational attainment (having a degree or not) and whether employed or not. We assigned the income domain score of IMD to each participant based on the area where they lived (Office of National Statistics, 2011). We then categorised participants according to quintiles of the distribution of income domain of IMD in England in 2010. We did not use the overall IMD score because it includes domains reflecting access to health services and health disability, which may be closely related to barriers to presentation.

We assessed whether cancer awareness or barriers score varied between socio-demographic subgroups using Kruskal-Wallis tests. We also examined the extent to which the socio-demographic factors were associated with each other in order to understand whether participants were equally distributed across socio-demographic subgroups. We examined the association between different socio-demographic factors (independent variables) and both recognition of individual cancer symptoms and perception of each barrier to presentation (dependent variables), using logistic regression models $(P<0.001$ level of significance). In the multivariable logistic regression model, we controlled for a priori confounders; age group, gender and area income deprivation. In sensitivity analyses, we repeated the multivariable logistic regression including only the surveys that used random probability sampling to find out whether the results were affected by the inclusion of studies with less robust sampling. We also compared results of telephone and face-to-face interviews to assess whether our conclusions would be different depending on the data collection mode.

To identify the best approach in handling missing data, we tested for systematic differences between the observed and missing data. We found no clear patterns of missingness in relation to our key variables - gender, age and area income deprivation. Nearly, all participants (99.9\%) had data on gender. Data were missing on age group in surveys that had used non-standard age group categorisations, which could not be aligned with those used in the other surveys (5\%). Participants with missing data on area income deprivation (18\%) mostly lived in particular areas, such as North London, Merseyside and Cheshire, where participants' postcodes, which are needed to assign area income deprivation, had not been collected (Supplementary Material 2). In the remaining surveys, the participants with missing postcodes accounted for not $>6 \%$ overall. Because of this relatively small proportion of missing data, their impact on the estimates is likely to be marginal. Overall, the missingness mechanism is very likely to be missing completely at random (MCAR) for age, gender and area income deprivation.

We used a complete-case analysis approach in which we analysed data from participants with complete data on gender, age group and area income deprivation. This approach-listwise deletion of participants with missing data on covariates-is 
recommended where data are MCAR (Allison, 2002). It outperforms more sophisticated approaches, such as multiple imputation, if there is no association between the probability of missing data for both dependent and independent variables (Allison, 2002). The sample size remained large $(n=38630)$. All analyses were done using Stata 12.1 (STATA Corp, 2012).

\section{RESULTS}

We collated data on 49270 adult participants living in 94 Primary Care Trust areas (PCTs) across England during 2009/2011 (Supplementary Material 2). At the time of the survey, PCTs were the National Health Service (NHS) organisations responsible for local health strategy, and commissioning and providing most health services in England ( $n=151$ PCTs in total at the time). The full sample $(n=49270)$ and the sample used in our analyses $(n=38630)$ had similar socio-demographic characteristics (Table 1). The gender and age distribution of our sample was similar to that of the general population of England, where just over half of the population was female; about a third was between 15 and $34(32 \%)$, and between 35 and 54 (34\%) years of age, 25\% was aged 55-74 years and $9 \%$ was aged $75+$ years, according to 2010 population estimates (Office for National Statistics, 2012). However, our sample was of lower SEP on average than the English population as measured by income domain of IMD (Office of National Statistics, 2011).

Age was associated with employment status, as $95 \%$ of the $75+$ -year-olds were retired, whereas $\sim 73 \%$ of the $35-54$-year-olds and $60 \%$ of the $15-34$-year-olds were employed $(P<0.0001)$. Most single participants were aged 15-34 years (58\%), most married participants or those living with a partner (we will refer to this group as 'married') were aged between 35 and 74 years (78\%) and most separated/divorced/widowed people (we will refer to this group as 'separated') were aged between 55 and 74 years (80\%; $P<0.0001)$. More separated and single participants lived in the most deprived areas (37\%, respectively) than those who were married $(30 \% ; P<0.0001)$. More participants without a degree lived in the most deprived areas (85\%) than those who had a degree $(P<0.0001)$.

On average, participants recognised 7.2 out of 9 cancer symptoms (Table 1 ), and $<40 \%$ of them recognised all nine cancer symptoms. Participants identified on average 1.8 barriers to presentation out of a possible 10. About two-thirds of participants (62\%) identified at least one barrier to presentation, and approximately a third of all participants $(30 \%)$ reported three or more barriers. There were significant differences between sociodemographic groups in cancer awareness and barriers score, although the mean number of reported barriers did not vary by area income deprivation (Table 1).

Recognition of individual cancer symptoms. Participants most frequently recognised 'unexplained lump or swelling' (94\%), and least frequently recognised 'persistent cough or hoarseness' and 'sore that does not heal' (68\%) as potential cancer symptoms (Figure 1).

Age group, gender, marital status, educational level, employment status and area income deprivation were all associated with recognition of each cancer symptom in the multivariable logistic

Table 1. Socio-demographic characteristics of the full and complete-case sample, and recognition of cancer symptoms and reported barriers to presentation in complete-case sample

\begin{tabular}{|c|c|c|c|c|}
\hline Sample & Full sample, n (\%) & Complete-case sample, $n(\%)$ & Mean recognised symptoms (s.d.) & Mean identified barriers (s.d.) \\
\hline Total & $49270(100)$ & $38630(100)$ & $7.2(2.1)$ & $1.8(2.2)$ \\
\hline \multicolumn{5}{|l|}{ Gender } \\
\hline Women & $26987(55)$ & $21606(56)$ & $7.4(2.0)^{a}$ & $1.9(2.2)^{a}$ \\
\hline Men & $22225(45)$ & $17024(44)$ & $7.0(2.2)$ & $1.7(2.1)$ \\
\hline Missing & $58(0)$ & & & \\
\hline \multicolumn{5}{|l|}{ Age (years) } \\
\hline $15-34$ & $12777(26)$ & $10032(26)$ & $6.7(2.3)^{a}$ & $2.3(2.4)^{a}$ \\
\hline $35-54$ & $17571(36)$ & $14280(37)$ & $7.3(2.0)$ & $1.9(2.2)$ \\
\hline $55-74$ & $13982(28)$ & $12028(31)$ & $7.6(1.8)$ & $1.4(1.9)$ \\
\hline $75+$ & $2506(5)$ & $2290(6)$ & $7.1(2.2)$ & $1.3(1.8)$ \\
\hline Missing & $2434(5)$ & & & \\
\hline \multicolumn{5}{|l|}{ Marital status } \\
\hline Married & $21956(44)$ & $16884(44)$ & $7.5(1.9)^{a}$ & $1.7(2.1)^{a}$ \\
\hline Single & $10168(21)$ & $7631(20)$ & $6.9(2.3)$ & $1.9(2.4)$ \\
\hline Separated & $8262(17)$ & $6075(16)$ & 7.5 (1.9) & $1.6(2.0)$ \\
\hline Missing & $8884(18)$ & $8040(21)$ & & \\
\hline \multicolumn{5}{|l|}{ Education } \\
\hline With degree & $9761(20)$ & $6932(18)$ & $7.7(1.8)^{a}$ & $1.8(2.0)^{a}$ \\
\hline Without degree & 30015 (61) & $23661(61)$ & $7.3(2.1)$ & $1.7(2.1)$ \\
\hline Missing & 9494 (19) & $8037(21)$ & & \\
\hline \multicolumn{5}{|l|}{ Employment } \\
\hline Employed & $20803(42)$ & $15601(40)$ & $7.4(2.0)^{a}$ & $1.9(2.1)^{a}$ \\
\hline Not employed & 9296 (19) & 7211 (19) & $6.9(2.2)$ & $2.0(2.3)$ \\
\hline Retired & $10574(22)$ & $8051(21)$ & $7.6(1.9)$ & $1.2(1.7)$ \\
\hline Missing & 8597 (18) & $7767(20)$ & & \\
\hline \multicolumn{5}{|c|}{ Quintile of area income deprivation } \\
\hline 1 (Least deprived) & $4735(10)$ & $4595(12)$ & $7.6(1.9)^{a}$ & $1.8(2.0)$ \\
\hline 2 & $5661(11)$ & $5490(14)$ & 7.5 (1.9) & $1.8(2.1)$ \\
\hline 3 & 8424 (17) & $8118(21)$ & $7.4(2.0)$ & $1.8(2.2)$ \\
\hline 4 & $8733(18)$ & $8316(22)$ & $7.1(2.2)$ & $1.9(2.1)$ \\
\hline 5 (Most deprived) & $12766(26)$ & $12111(31)$ & $7.0(2.2)$ & $1.9(2.2)$ \\
\hline Missing & $8951(18)$ & & & \\
\hline
\end{tabular}




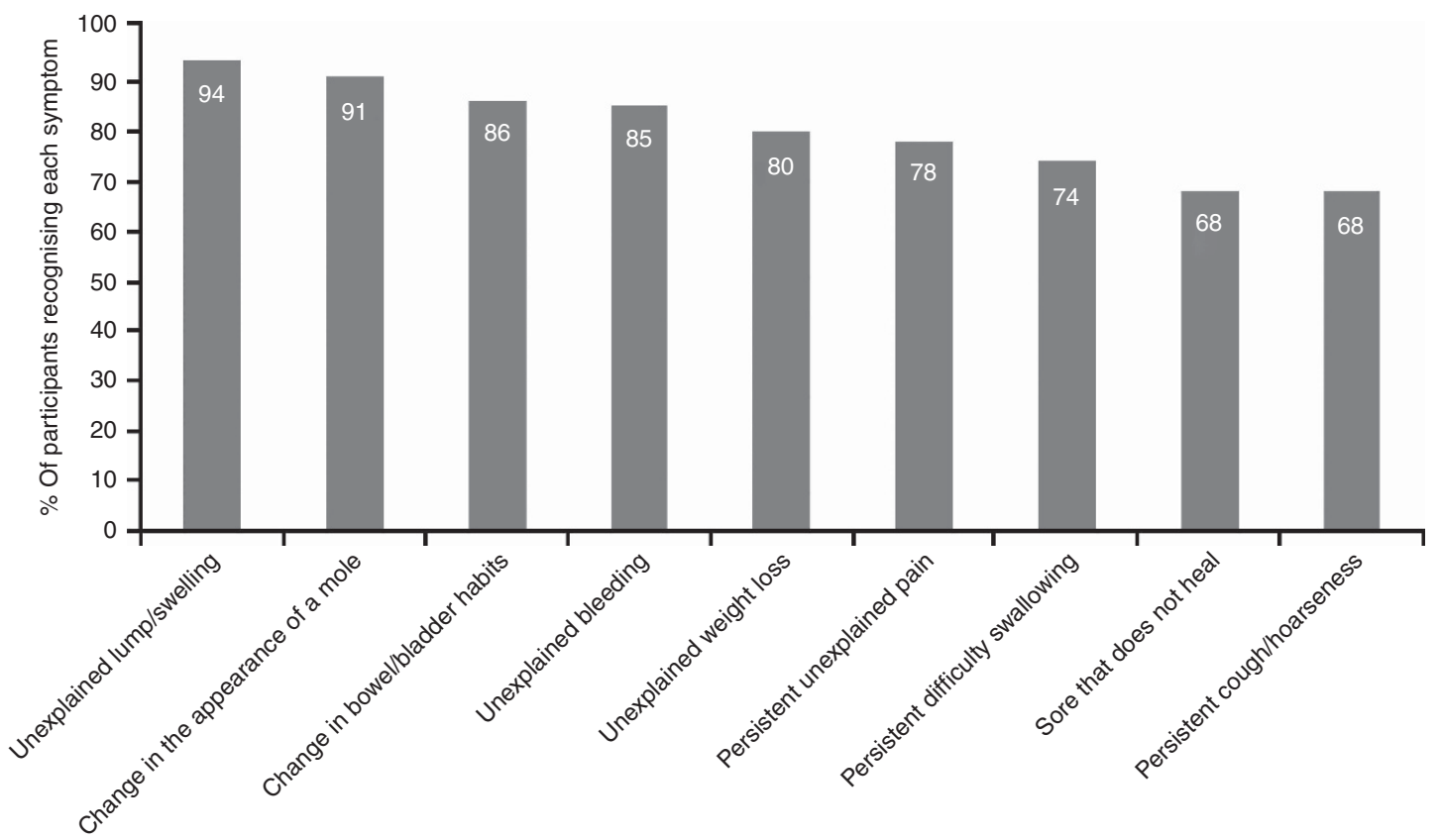

Figure 1. Frequency of recognition of cancer symptoms.

regression analysis (Table 2). Women were more likely than men to recognise each cancer symptom, except 'persistent unexplained pain'. We found the largest gender difference for recognition of 'change in the appearance of a mole'. The odds of recognising this symptom were $60 \%$ higher in women than men $(\mathrm{OR}=1.60 ; 95 \%$ confidence interval (CI): 1.46-1.75). Participants aged between 55 and 74 years were most likely to recognise each of the nine possible symptoms of cancer. The youngest participants were least likely to recognise six of the symptoms (unexplained bleeding, persistent cough, changes in bowel/bladder habits, difficulty in swallowing, sore that does not heal and unexplained weight loss). The oldest participants were less likely than those aged 55-74 years to recognise 'unexplained lump or swelling', 'unexplained persistent pain' and 'change in the appearance of a mole'. Participants who were single were least likely to recognise all cancer symptoms.

We found a strong trend suggesting that the lower the SEP, the less likely the participants were to recognise each cancer symptom. Participants who were unemployed, the least educated and those living in areas with highest area income deprivation were least likely to recognise all cancer symptoms. The difference was most marked for 'change in appearance of a mole'. Participants living in areas with the highest income deprivation had significantly lower odds of recognising this symptom than those from the most affluent areas (OR $=0.37$; 95\% CI: 0.31-0.45). In addition, the odds of recognising 'change in appearance of a mole' as a potential cancer symptom were $\sim 49-56 \%$ lower in participants without a degree and the unemployed, respectively, in comparison with their graduate or employed counterparts $(\mathrm{OR}=0.67 ; 95 \% \mathrm{CI}$ : $0.57-0.79$; and, $\mathrm{OR}=0.64 ; 95 \% \mathrm{CI}: 0.56-0.73$, respectively). The results of the unadjusted model were similar (Supplementary Material 3). The sensitivity analysis to examine the effect of less robust survey methods showed similar patterns, suggesting that the results were unaffected by survey design. We also found no differences in relation to the modes of interviewing-face-to-face and telephone interviews produced similar results.

Barriers to symptomatic presentation. Approximately a third of all participants (30\%) reported that 'worry about what the doctor might find' might put them off going to the doctor (Figure 2). Participants were least likely to report that difficulties in arranging transport to the doctor's surgery would be a barrier to presentation $(6 \%)$.

Age group, gender, marital status, educational level, employment status and area income deprivation were all associated with reporting each barrier to presentation in the multivariable models (Table 3). Women were more likely than men to report each barrier to presentation, except being 'too busy' to make time to go to the doctor and difficult to 'arrange transport'. Emotional barriers, such as feeling 'too scared' or 'too embarrassed', 'worry about what the doctor might find' and 'not feeling confident enough to talk about the symptoms', were particularly common among women. We found the largest gender difference for reporting being 'too scared' to go to the doctor's surgery-the odds were $40 \%$ higher in women than men $(\mathrm{OR}=1.40 ; 95 \%$ CI: 1.31-1.50). All barriers to presentation, except transport difficulties, decreased with age. The youngest participants most frequently reported barriers to presentation compared with 55-74-year-old participants, especially being 'too busy' $(\mathrm{OR}=3.07 ; 95 \% \mathrm{CI}: 2.79-3.38)$. Arranging transport to the doctor's surgery was the only exception, which $75+$ year-olds were much more likely to report than 55-74-year-old participants $(\mathrm{OR}=2.30$; 95\% CI: $1.87-2.82)$.

Participants who were single most frequently reported barriers to presentation, especially emotional barriers (feeling 'too embarrassed', 'too scared', 'would not feel confident talking about my symptoms' and 'worry about what the doctor might find'). However, married participants more frequently reported that being 'too busy' or 'worried about many other things' might put them off going to the doctor than either separated or single participants. Separated participants had $\sim 60 \%$ higher odds of reporting that arranging transport to go to the doctor's surgery would be a barrier to presentation than married participants $(\mathrm{OR}=1.62$; 95\% CI: $1.36-1.93)$.

We found a trend suggesting that participants with lower SEP, on both individual and area-based indicators, were more likely to identify barriers to presentation. The trend was particularly strong for emotional barriers. Participants of lower SEP had 20\% higher odds of reporting that feeling 'too embarrassed' might prevent them from going to the doctor than those of higher SEP (Table 3). We found the largest difference for the barrier 'it would be difficult for me to arrange transport to the doctor's surgery' (graduate 


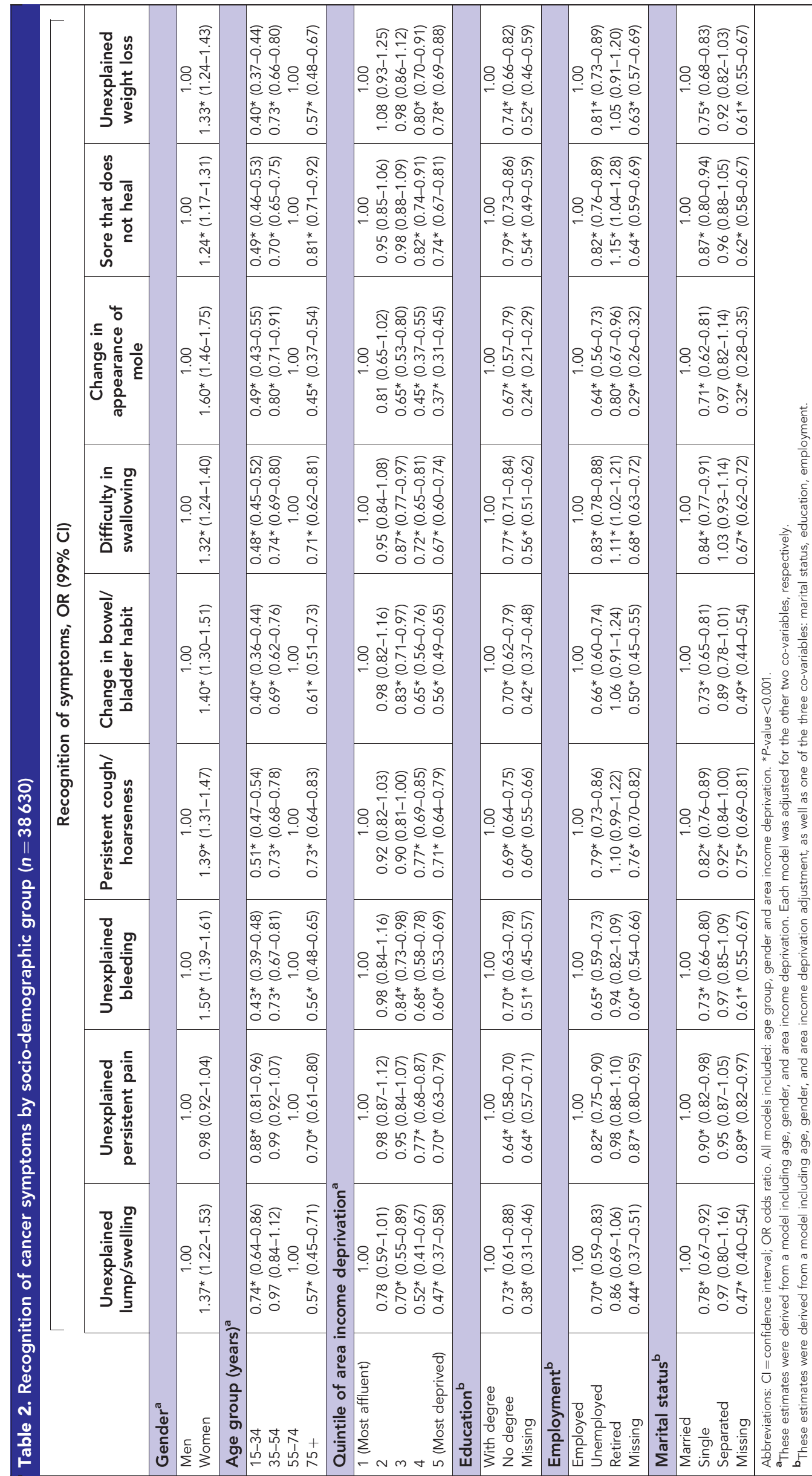




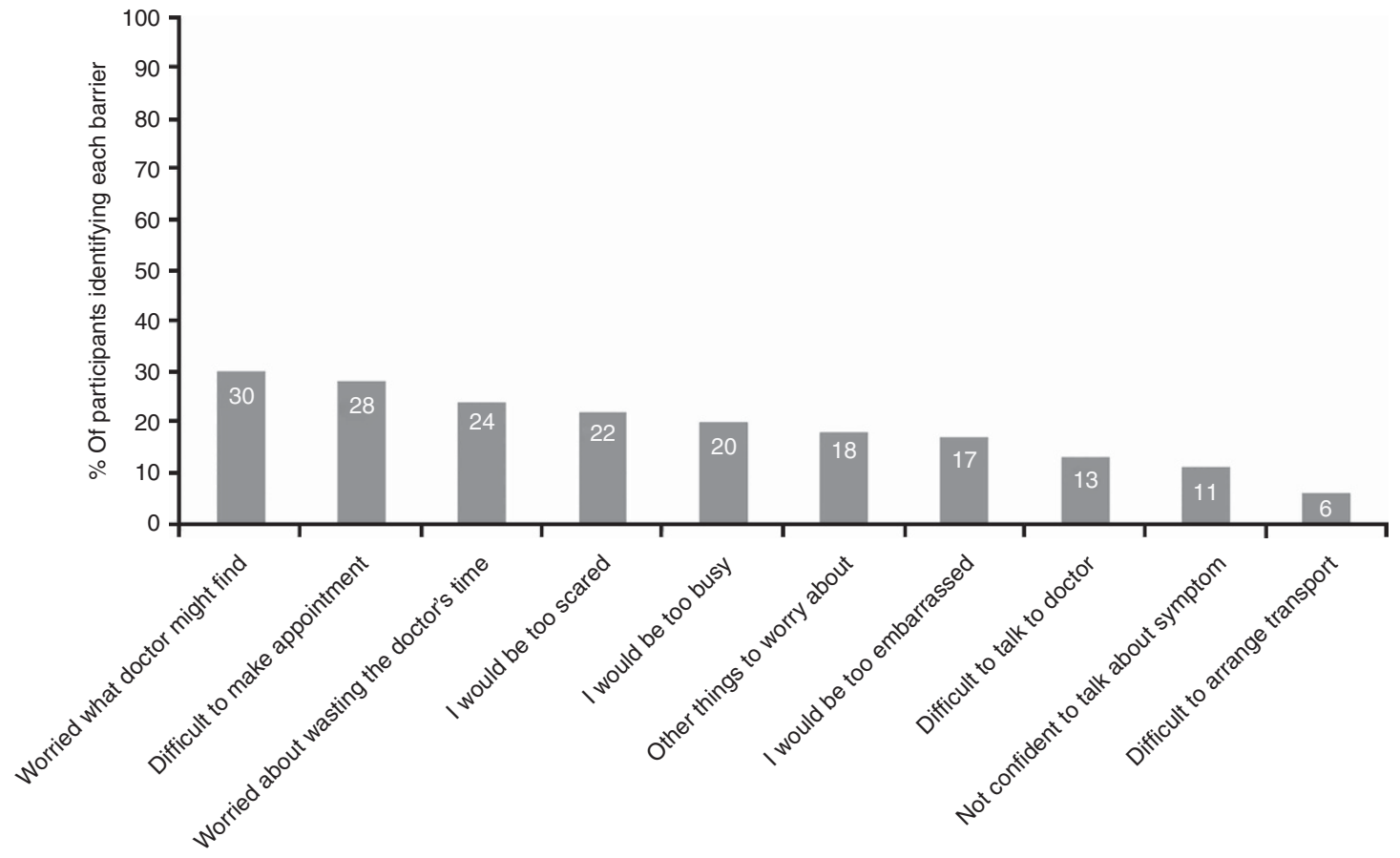

Figure 2. Frequency of reported barriers to symptomatic presentation.

vs non-graduate: $\mathrm{OR}=1.34$; 95\% CI: $1.11-1.61$; unemployed $v$ s employed: $\mathrm{OR}=1.59$; $95 \% \mathrm{CI}: 1.34-1.89$; and most deprived areas vs least deprived: $\mathrm{OR}=1.51 ; 95 \% \mathrm{CI}$ : $1.27-1.88)$. Less educated participants, the unemployed and those with the highest area income deprivation were, however, less likely to report being 'too busy' and 'worry about many other things'. The results of the unadjusted model were similar (Supplementary Material 4). The sensitivity analysis suggested that the results were unaffected by survey design. We also found no differences in relation to the modes of interviewing-face-to-face and telephone interviews produced similar results.

\section{DISCUSSION}

This study highlighted differences in the way that population subgroups recognise cancer symptoms and their reasons to put off going to the doctor. People with low SEP, the youngest and oldest, and those who were single had the lowest cancer awareness, and also found numerous reasons to deter them from seeking medical help. Women had better awareness of cancer symptoms and reported more barriers to help seeking than men.

Strengths and limitations. This is the first study to collate and analyse a large data set on cancer awareness and barriers to symptomatic presentation from local cross-sectional surveys across England. To the best of our knowledge, this is the biggest population-representative study of public cancer awareness. The uniquely large sample allowed us to detect and quantify sociodemographic differences in cancer awareness and barriers with much higher statistical power and precision than any previous study, assess a broader scope of socio-demographic factors, control for potential confounders and conduct comprehensive sensitivity analyses. We used a validated measure of cancer awareness, adjusted our analyses for potential confounders and conducted comprehensive sensitivity analyses. About a quarter of the participants lived in the most deprived quintile of areas of deprivation, a much larger number than in other studies. This means we could provide more robust results in relation to the underprivileged population, with better control for potential confounders. This is the first study that allowed us to compare the effect of both individual and area-based measures of SEP on cancer symptom awareness and barriers to presentation. It has been suggested to use both individual and area-based measures of socio-economic status in surveys, because they may have different or independent effects on health (Davey Smith et al, 1998). Assessing only area-based measures of SEP can lead to poor understanding of which individual characteristics contribute to particular health outcomes, while assessing only individual measures may lead to misunderstanding the role of wider socio-economic context in health (Pickett and Pearl, 2001). The fact that we observed similar effects using both individual and areabased SEP measures made us more confident in our findings.

Possible limitations are that approximately half of the data were collected in surveys that did not use random probability sampling, which could have made the sample less representative. However, when we repeated analyses using data collected from participants selected by random probability sampling only, our results were very similar. Some socio-demographic groups may have a greater propensity to give 'yes' responses during interviews (acquiescence bias) (Bowling, 2005). This is unlikely to fully explain the observed results, as the groups who had more 'yes' responses in relation to symptom awareness did not give more 'yes' responses in relation to barriers. Some socio-demographic groups may have a greater propensity to give 'socially desirable' answers in relation to some of the questions about barriers, especially as most data were collected using face-to-face interviews (Bowling, 2005). For example, being 'too busy' may be seen as more socially desirable among groups with higher SEP or men (Sullivan, 2008). Potential social desirability and interviewer bias were reduced by reassuring participants of confidentiality and anonymity, and training the interviewers to ensure they appear neutral during data collection. Recognition of symptoms may have been somewhat overestimated, because some participants could have guessed the correct answers to the prompted questions (Robb et al, 2009).

Comparison of findings with previous literature. The youngest age group had lower cancer symptom awareness than the middleaged group, which has been found in previous studies (Brunswick et al, 2001; Robb et al, 2009). This is perhaps owing to their lower 


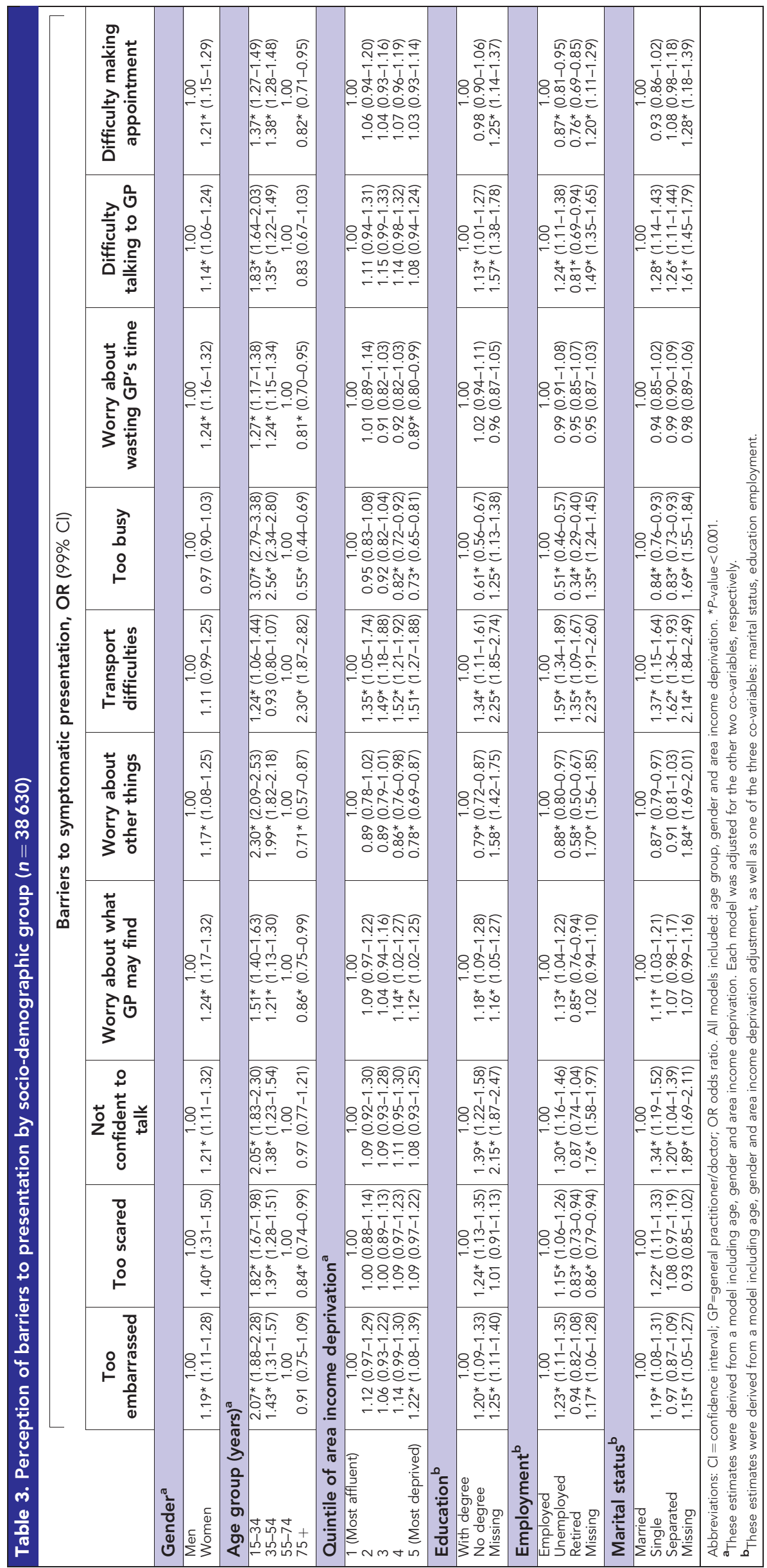


risk of being diagnosed with cancer, or because they are less likely than older people to have the experience of cancer among peers or relations. We also found that the oldest age group had lower awareness of cancer symptoms than the middle-aged group. Lumps, swellings and skin changes are common problems among the elderly, and therefore might not be perceived as a serious health threat (Bentley, 2003). Persistent pain is common among the over75 age group owing to conditions such as osteoarthritis, but is underreported (Jakobsson and Hallberg, 2002). Older people may believe that pain is an inevitable effect of the ageing process.

The oldest age group was least likely to report barriers to seeking help, expect for difficulties in arranging transport to the doctor's surgery. This contrasts with the findings of a study in East London, which found that women aged $65+$ years were more likely to report embarrassment, worry about wasting the doctor's time, fear and too many other things to worry about than younger women (Forbes et al, 2010). This may reflect the inner city setting of that study, which may not have been generalisable to all of England. However, that study, similar to ours, found that older people were more likely to have difficulty in arranging transport. Sensory and physical impairments may prevent them from driving or using public transport (Wagner et al, 2011), making them dependent on others for transport needs.

Cancer awareness was higher in women than men. Health is often perceived as a female domain, given that women have more contact with health services, because of their reproductive role and cultural expectations of caring for others. Previous studies reported higher cancer awareness in women than men (Brunswick et al, 2001; Robb et al, 2009). However, unlike other studies, we found no gender differences in recognition of 'unexplained, persistent pain'. This is in line with a recent systematic review that found no evidence that pain perception and pain sensitivity differ between men and women (Racine et al, 2012), so once pain is experienced both genders may attribute it to a potential health threat, such as cancer.

Women more frequently reported barriers to presentation, especially fear and embarrassment. Robb et al (2009), on the other hand, found no significant gender differences in reporting of barriers, which may be because that study was smaller and lacked power to show a statistically significant difference. Men may be culturally less willing to admit that they experience some barriers, in particular, embarrassment, fear or worry, perhaps perceiving this to be emasculating (Evans et al, 2005). Men are less frequent users of health services (Elliott et al, 2011), even after allowing for more consultations for reproductive health issues in women (Green and Pope, 1999), which suggests that they do indeed experience barriers to symptomatic presentation. It is possible that the CAM questionnaire does not measure those barriers that particularly affect men.

Single participants were least likely to recognise cancer symptoms, which is in agreement with previous findings (Brunswick et al, 2001; Robb et al, 2009). Our novel finding was that this group was also more likely to report barriers than married or separated participants. A possible explanation is that partners may be more likely to notice physical changes and encourage help seeking (Kaplan and Kronick, 2006). People with partners may be more likely to talk about their symptoms with others, which may motivate them to seek help (Burgess et al, 1998). Being single may also be a marker for low levels of social support, which has been associated with patient delay in presentation (Sundararajan et al, 2004).

Participants with lower SEP had a tendency to recognise fewer cancer symptoms. Most previous studies reported this trend (Brunswick et al, 2001; Robb et al, 2009), depending on which SEP measures were used. Our study and Brunswick et al (2001) found that having a degree or $>15$ years of full-time education significantly increased cancer awareness, which was not reported in the study by Robb et al (2009). Brunswick et al (2001) found no significant differences in cancer awareness of unskilled workers and those in professional or skilled manual occupations, although there was a difference between unskilled and intermediate/small employers. Robb et al (2009) observed highly significant differences between all occupational groups. These inconsistencies may be owing to lack of statistical power of the studies or potential confounders, which have not been included in analyses. Our study showed robust evidence that recognition of each symptom gradually decreased with each quintile of area income deprivation, which was significant after controlling for confounders. We also showed that the unemployed had low cancer awareness, which none of the previous studies assessed. The underprivileged tend to have less health-protecting resources in their environment, such as access to adequate nutrition or health services (Adler and Rehkopf, 2008). They may be more likely to interpret symptoms as 'normal' because of limited access to health information, linked with lack of education (Brunswick et al, 2001) or due to their unhealthy lifestyle (Dixon-Woods et al, 2006).

Participants with lower SEP reported increased worry about what the doctor might find and embarrassment. Fear of cancer and fatalistic beliefs about cancer prevention are common among underprivileged people, especially those with low educational attainment (Powe and Finnie, 2003). The underprivileged may experience complex socio-cultural difficulties, such as feeling intimidated by health-care professionals, or perceive social distance owing to the difference in income and social status between themselves and their doctor (Dixon-Woods et al, 2006). On the other hand, participants with higher SEP most frequently reported that being too busy or worrying about many other things might prevent them from seeking medical help. Those with high career aspirations may be under pressure to work long hours and more readily accept additional work responsibilities, which may limit their opportunities to engage in health preventive behaviour. However, it may also be part of the professional narrative of high status groups who are 'Income Rich, Time Poor' and subjective experience of 'busyness', which is commonly associated with status distinction and affluence (Sullivan, 2008).

Implications. A guiding principle of the NHS Cancer Plan (Department of Health, 2000), and every subsequent national strategy for cancer, is that early cancer detection and diagnosis saves lives, because treatments are most likely to be effective in people who are diagnosed at an earlier stage. Public health campaigns, aimed at encouraging early presentation and downstaging cancer, could be more targeted to specific population groups and tailored according to their needs. Our study provided the most robust evidence on socio-demographic differences in cancer awareness and barriers to help seeking, required to improve targeting of these campaigns. More specifically, men might benefit more from educational campaigns aimed at increasing their awareness of cancer symptoms. Psychological campaigns aimed at alleviating cancer-related fears and embarrassment in relation to seeking help may be more beneficial for women. Policy to promote earlier symptomatic presentation should also include strategies to promote confidence to discuss potential symptoms, and allay embarrassment among the underprivileged and people with low levels of social support. We need to ensure that these groups, and older people, have appropriate and affordable transport options to reach health services. While it is important to ensure that younger people are equipped with the knowledge and skills to seek help promptly, encouraging health service use among those at lowest risk of cancer may raise anxiety levels and increase burden on health services at the expense of those at higher risk.

Our study suggests that different socio-demographic groups have different levels of cognitive and attitudinal readiness to seek medical help, which need to be addressed to tackle inequalities in access to services. This is in line with the Department of Health's Improving Outcomes: A Strategy for Cancer, which aims to reduce 
inequalities in cancer services and outcomes by promoting early diagnosis and optimal treatments among the underprivileged (Department of Health, 2011). However, tackling the problem of health inequalities requires more complex solutions that go beyond simply increasing access to services. In countries with universal health-care system, such as England, access is free at the point of service, but this does not mean that all groups can use services with equal ease (Dixon-Woods et al, 2006). People with low SEP may lack the skills necessary to negotiate their ways to use the health services (Dixon-Woods et al, 2006). Therefore, going to poor communities to raise their cancer awareness and reassuring people that early detection saves lives may be a better way for health-care professionals to reach the underprivileged. Another approach is to use narratives of cancer survivors from poor communities in adverts, promoting early presentation. This may be more helpful than using images of doctors listing the possible symptoms of cancer, which might be difficult to relate to.

The 'Be Clear on Cancer' campaigns, launched in England in 2010, aim to promote earlier diagnosis and increase public awareness of symptoms of different types of cancer (Cancer Research UK, 2011). There have been promising early results. The first national lung campaign suggested better recognition of persistent cough as an early cancer symptom, along with a shift towards an early-stage distribution of non-small cell lung cancer, and increase in surgical resection rate for patients diagnosed during the campaign in comparison with the same period the previous year (Ironmonger et al, 2014). High media coverage of breast cancer in comparison with other most common cancers (Konfortion et al, 2014 ) could explain why over $90 \%$ of our participants recognised an unexplained lump as a possible symptom. Other types of cancer require more media attention and targeted campaigns to help people recognise the early symptoms more effectively.

Future research should explore whether cancer symptom awareness is directly or indirectly associated with cancer survival, and what are the underlying mechanisms of this interaction. It is possible that the mechanism could be delayed presentation, which could contribute to advanced-stage diagnosis and poor cancer survival. This hypothesis has been tested in the ongoing NAEDI research projects (Cancer Research UK, 2011). Our study quantified the socio-demographic differences in cancer awareness and barriers to presentation, and suggested how to use these to better target heath campaigns. However, future studies should pilot the targeted campaigns and determine whether they are costeffective before implementing them nationally. Finally, understanding the reasons why people in our sample identified certain barriers, for example, why people worry about wasting the doctor's time, could further improve the effectiveness of future campaigns. Our findings could contribute to improving cancer survival in England to match the best in Europe by helping to develop targeted campaigns promoting early presentation of cancer symptoms.

\section{ACKNOWLEDGEMENTS}

This study is part of a $\mathrm{PhD}$ studentship funded by the Policy Research Unit in Cancer Awareness, Screening, and Early Diagnosis, which in turn receives funding from the Department of Health Policy Research Programme. It is collaboration between researchers from seven institutions (Queen Mary University of London, UCL, King's College London, London School of Hygiene and Tropical Medicine, Hull York Medical School, Durham University and Peninsula Medical School), For the KCL, UCL and Cancer Research UK Team developing the CAM questionnaire. For funding the surveys: Cancer Research UK; the National Cancer Action Team and Department of Health. For coordinating the surveys: Dr Kathy Elliott and Dr Emily Power. For collecting the data: the cancer networks and data collection agencies, including Public and Ipsos MORI. For help with collating and cleaning the datasets: Charlotte Blackmore, Dr Farhana Haseen, Dharmishta Parmar. For taking part: all the survey participants.

\section{CONFLICT OF INTEREST}

The authors declare no conflict of interest.

\section{REFERENCES}

Abdel-Rahman M, Stockton D, Rachet B, Hakulinen T, Coleman MP (2009) What if cancer survival in Britain were the same as in Europe: how many deaths are avoidable? Br J Cancer 101(Suppl 2): S115-S124.

Adler NE, Rehkopf DH (2008) US disparities in health: descriptions, causes, and mechanisms. Annu Rev Public Health. 29: 235-252.

Allison PD (2002) Missing Data. Sage University Papers Series: Quantitative Applications in the Social Sciences, Vol. 136. Sage Publications, Inc.: Thousand Oaks, CA, USA.

Bentley J (2003) Barriers to accessing health care: the perspective of elderly people within a village community. Int J Nurs Stud 40(1): 9-21.

Bowling A (2005) Mode of questionnaire administration can have serious effects on data quality. J Public Health 27(3): 281-291.

Brunswick N, Wardle J, Jarvis MJ (2001) Public awareness of warning signs for cancer in Britain. Cancer Causes Control 12(1): 33-37.

Burgess CC, Ramirez AJ, Richards MA, Love SB (1998) Who and what influences delayed presentation in breast cancer? Br J Cancer 77(8): 1343-1348.

Cancer Research UK (2011) National Awareness and Early Diagnosis Initiative (NAEDI). Available at http://www.cancerresearchuk.org/healthprofessional/early-diagnosis-activities/national-awareness-and-earlydiagnosis-initiative-naedi (accessed 12 October 2011).

Coleman M, Forman D, Bryant H, Butler J, Rachet B, Maringe C, Nur U, Tracey E, Coory M, Hatcher J, McGahan C, Turner D, Marrett L, Gjerstorff M, Johannesen T, Adolfsson J, Lambe M, Lawrence G, Meechan D, Morris E, Middleton R, Steward J, Richards M. The IMWG (2011) Cancer survival in Australia, Canada, Denmark, Norway, Sweden, and the UK, 1995 2007 (the International Cancer Benchmarking Partnership): an analysis of population-based cancer registry data. Lancet 377: 127-138.

Davey Smith G, Hart C, Watt G, Hole D, Hawthorne V (1998) Individual social class, area-based deprivation, cardiovascular disease risk factors, and mortality: the Renfrew and Paisley Study. J Epidemiol Community Health. 52(6): 399-405.

Department for Communities and Local Government. (2010) The English Indices of Deprivation 2010 File Notes. Available from http://data.gov.uk/ dataset/index-of-multiple-deprivation (accessed 9 May 2013).

Department of Health (2000) The NHS Cancer Plan: a plan for investment, a plan for reform. Department of Health: London, UK.

Department of Health (2011) Assessment of the Impact on Equalities (AIE). Published alongside Improving Outcomes: A Strategy for Cancer. Department of Health: London, UK.

Dixon-Woods M, Cavers D, Agarwal S, Annandale E, Arthur A, Harvey J, Hsu R, Katbamna S, Olsen R, Smith L (2006) Conducting a critical interpretive synthesis of the literature on access to healthcare by vulnerable groups. BMC Med Res Methodol 6(1): 35.

Elliott AM, McAteer A, Hannaford PC (2011) Revisiting the symptom iceberg in today's primary care: results from a UK population survey. BMC Fam Pract 12(1): 16 .

Evans REC, Brotherstone H, Miles A, Wardle J (2005) Gender differences in early detection of cancer. J Mens Health Gender 2(2): 209-217.

Forbes L, Atkins L, Haste F, Layburn J, Ramirez AJ (2010) Awareness of breast cancer among women in inner North East London. King's College London, Cancer Research UK. http://www.cancerresearchuk.org/prod_consump/ groups/cr_common/@nre/@hea/documents/generalcontent/cr_052797.pdf.

Forbes L, Simon A, Warburton F, Boniface D, Brain K, Dessaix A, Donnelly C, Haynes K, Hvidberg L, Lagerlund M (2013) Differences in cancer awareness and beliefs between Australia, Canada, Denmark, Norway, Sweden and the UK (the International Cancer Benchmarking Partnership): do they contribute to differences in cancer survival? Br J Cancer 108: 292-300.

Forbes LJL, Warburton F, Richards MA, Ramirez AJ (2014) Risk factors for delay in symptomatic presentation: a survey of cancer patients. Br J Cancer, Vol. 1-8. 
Green CA, Pope CR (1999) Gender, psychosocial factors and the use of medical services: a longitudinal analysis. Soc Sci Med 48(10): 1363-1372.

Ironmonger L, Ohuma E, Ormiston-Smith $\mathrm{N}$, Gildea $\mathrm{C}$, Thomson $\mathrm{C}$, Peake $\mathrm{M}$ (2014) An evaluation of the impact of large-scale interventions to raise public awareness of a lung cancer symptom. $\mathrm{Br} J$ Cancer 112: 207-216.

Jakobsson U, Hallberg IR (2002) Pain and quality of life among older people with rheumatoid arthritis and/or osteoarthritis: a literature review. J Clin Nurs 11(4): 430-443.

Kaplan RM, Kronick RG (2006) Marital status and longevity in the United States population. J Epidemiol Community Health 60(9): 760-765.

Konfortion J, Jack RH, Davies EA (2014) Coverage of common cancer types in UK national newspapers: a content analysis. BMJ Open 4(7): e004677.

Linsell L, Burgess CC, Ramirez AJ (2008) Breast cancer awareness among older women. $\mathrm{Br} J$ Cancer 99: 1221-1225.

Lyratzopoulos G, Abel GA, Barbiere JM, Brown CH, Rous BA, Greenberg DC (2012a) Variation in advanced stage at diagnosis of lung and female breast cancer in an English region 2006-2009. Br J Cancer 106(6): 1068-1075.

Lyratzopoulos G, Abel GA, Brown CH, Rous BA, Vernon SA, Roland M, Greenberg DC (2012b) Socio-demographic inequalities in stage of cancer diagnosis: evidence from patients with female breast, lung, colon, rectal, prostate, renal, bladder, melanoma, ovarian and endometrial cancer. Ann Oncol 24(3): 843-850.

Macleod U, Mitchell ED, Burgess C, MacDonald S, Ramirez AJ (2009) Risk factors for delayed presentation and referral of symptomatic cancer: evidence for common cancers. Br J Cancer 101: s92-s101.

Maringe C, Walters S, Rachet B, Butler J, Fields T, Finan P, Maxwekk R, Nedrebo B, Pahlman L, Sjovall A, Spigelman A, Engholm G, Gavin A, Gjerstorff M, Hatcher J, Johannesen T, Morris E, McGahan C, Tracey E, Turner D, Richards M, Coleman MP (2013) Stage at diagnosis and colorectal cancer survival in six high-income countries: A populationbased study of patients diagnosed during 2000-2007. Acta Oncol 52(5): 919-932.

Møller H, Sandin F, Bray F, Klint A, Linklater KM, Purushotham A, Robinson D, Holmberg L (2010) Breast cancer survival in England, Norway and Sweden: A population-based comparison. Int J Cancer 127(11): 2630-2638.

NICE (2007) Behaviour change at population, community and individual levels. National Institute for Health and Clinical Excellence: London, UK.

Office for National Statistics (2012) 2011 Census: Population Estimates for the United Kingdom - 27 March 2011. Available from http:// www.ons.gov.uk/ons/rel/census/2011-census/population-and-householdestimates-for-the-united-kingdom/stb-2011-census-population-estimatesfor-the-united-kingdom.html (accessed 29 July 2013).

Office of National Statistics (2011) English Indices of Deprivation 2010: Income Domain. Department for Communities and Local Government: London, Available from https://www.gov.uk/government/statistics/english-indicesof-deprivation-2010 (accessed 15 March 2013).
Pickett KE, Pearl M (2001) Multilevel analyses of neighbourhood socioeconomic context and health outcomes: a critical review. J Epidemiol Community Health 55(2): 111-122.

Powe BD, Finnie R (2003) Cancer fatalism: the state of the science. Cancer Nurs 26(6): 454-465.

Power E, Wardle J (2015) Change in public awareness of symptoms and perceived barriers to seeing a doctor following Be Clear on Cancer campaigns in England. Br J Cancer.

Rachet B, Ellis L, Maringe C, Chu T, Nur U, Quaresma M, Shah A, Walters S, Woods L, Forman D (2010) Socioeconomic inequalities in cancer survival in England after the NHS cancer plan. Br J Cancer 103(4): 446-453.

Racine M, Tousignant-Laflamme Y, Kloda LA, Dion D, Dupuis G, Choinière M (2012) A systematic literature review of 10 years of research on sex/ gender and experimental pain perception-Part 1: Are there really differences between women and men? Pain 153(3): 602-618.

Robb KA, Stubbings S, Ramirez A, Macleod U, Austoker J, Waller J, Hiom S, Wardle J (2009) Public awareness of cancer in Britain: a population-based survey of adults. Br J Cancer 101: s18-s23.

Simon AE, Waller J, Robb K, Wardle J (2010) Patient delay in presentation of possible cancer symptoms: the contribution of knowledge and attitudes in a population sample from the United Kingdom. Cancer Epidemiol Biomarkers Prev 19(9): 2272-2277.

STATA Corp L (2012) Stata 12 statistical software: College Station, TX, USA. Stubbings S, Robb KA, Waller J, Ramirez A, Austoker J, Macleod U, Hiom S, Wardle J (2009) Development of a measurement tool to assess public awareness of cancer. Br J Cancer 101: s13-s17.

Sullivan O (2008) Busyness, status distinction and consumption strategies of the income rich, time poor. Time Soc 17(1): 5-26.

Sundararajan V, Henderson T, Perry C, Muggivan A, Quan H, Ghali WA (2004) New ICD-10 version of the Charlson comorbidity index predicted in-hospital mortality. J Clin Epidemiol 57(12): 1288-1294.

Wagner JT, Mürib RM, Nefc T, Mosimannc UP (2011) Cognition and driving in older persons. Swiss Med Wkly 140: 1-8.

Walters S, Maringe C, Coleman MP, Peake MD, Butler J, Young N, Bergström S, Hanna L, Jakobsen E, Kölbeck K, Sundstrøm S, Engholm G, Gavin A, Gjerstorff ML, Hatcher J, Johannesen TB, Linklater KM, McGahan CE, Steward J, Tracey E, Turner D, Richards MA, Rachet B (2013) Lung cancer survival and stage at diagnosis in Australia, Canada, Denmark, Norway, Sweden and the UK: a population-based study, 2004-2007. Thorax 68: 1-14.

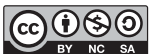

This work is licensed under the Creative Commons Attribution-Non-Commercial-Share Alike 4.0 International License. To view a copy of this license, visit http:// creativecommons.org/licenses/by-nc-sa/4.0/

Supplementary Information accompanies this paper on British Journal of Cancer website (http://www.nature.com/bjc) 